\title{
A NEW PROTOCOL FOR TEXTURE MAPPING PROCESS AND 2D REPRESENTATION OF RUPESTRIAN ARCHITECTURE
}

\author{
L. Carnevali ${ }^{1}$, M. Carpiceci ${ }^{1}$, A. Angelini ${ }^{2}$ \\ ${ }^{1}$ SAPIENZA University of Rome, Department of History, Representation and Restoration of Architecture - \\ laura.carnevali@uniroma1.it, marco.carpiceci@uniroma1.it \\ ${ }^{2}$ National Research Council of Italy - Institute for Technology Applied to Cultural Heritage - andrea.angelini@itabc.cnr.it
}

\section{Commission II, WG II/8}

KEY WORDS: Rupestrian Architecture; Hypogea, Laser Scanner, Image Projections, Equidistant Multiple Sections

\begin{abstract}
:
The development of the survey techniques for architecture and archaeology requires a general review in the methods used for the representation of numerical data. The possibilities offered by data processing allow to find new paths for studying issues connected to the drawing discipline. The research project aimed at experimenting different approaches for the representation of the rupestrian architecture and the texture mapping process. The nature of the rupestrian architecture does not allow a traditional representation of sections and projections of edges and outlines. The paper presents a method, the Equidistant Multiple Sections (EMS), inspired by cartography and based on the use of isohipses generated from different geometric plane. A specific paragraph is dedicated to the texture mapping process for unstructured surface models. One of the main difficulty in the image projection consists in the recognition of homologous points between image and point cloud, above all in the areas with most deformations. With the aid of the "virtual scan" tool a different procedure was developed for improving the correspondences of the image. The result show a sensible improvement of the entire process above all for the architectural vaults. A detailed study concerned the unfolding of the straight line surfaces; the barrel vault of the analyzed chapel has been unfolded for observing the paintings in the real shapes out of the morphological context.
\end{abstract}

\section{INTRODUCTION}

\subsection{The research project}

Since 2014 the research unit of the Sapienza University of Rome has dealt with the cataloguing and surveying of several examples of rupestrian architectures in Italy and Turkey (Cappadocia; Carpiceci, Inglese, 2015). The challenge was to experiment innovative forms of $3 \mathrm{D}$ and $2 \mathrm{D}$ representation in architecture and archeology, exploiting the most recent survey techniques. The development of range-data systems allowed to define accurate working protocols of data acquisition and processing in various disciplines. The integration with imagebased systems gives the possibilities to manage a large amount of data for studying and analyzing the architecture from new perspectives never reached before.

The research project aimed at experimenting different approaches for the representation of the rupestrian architecture and the texture mapping process.

In 2017, in the village of Sant'Angelo in Grotte (Italy), hypogea of the nineteenth-century church of San Pietro in Vincoli were surveyed (Fig.1). The choice of the case study has been imposed for the importance of such archaeological monument. The achieved results document the current state and could give new

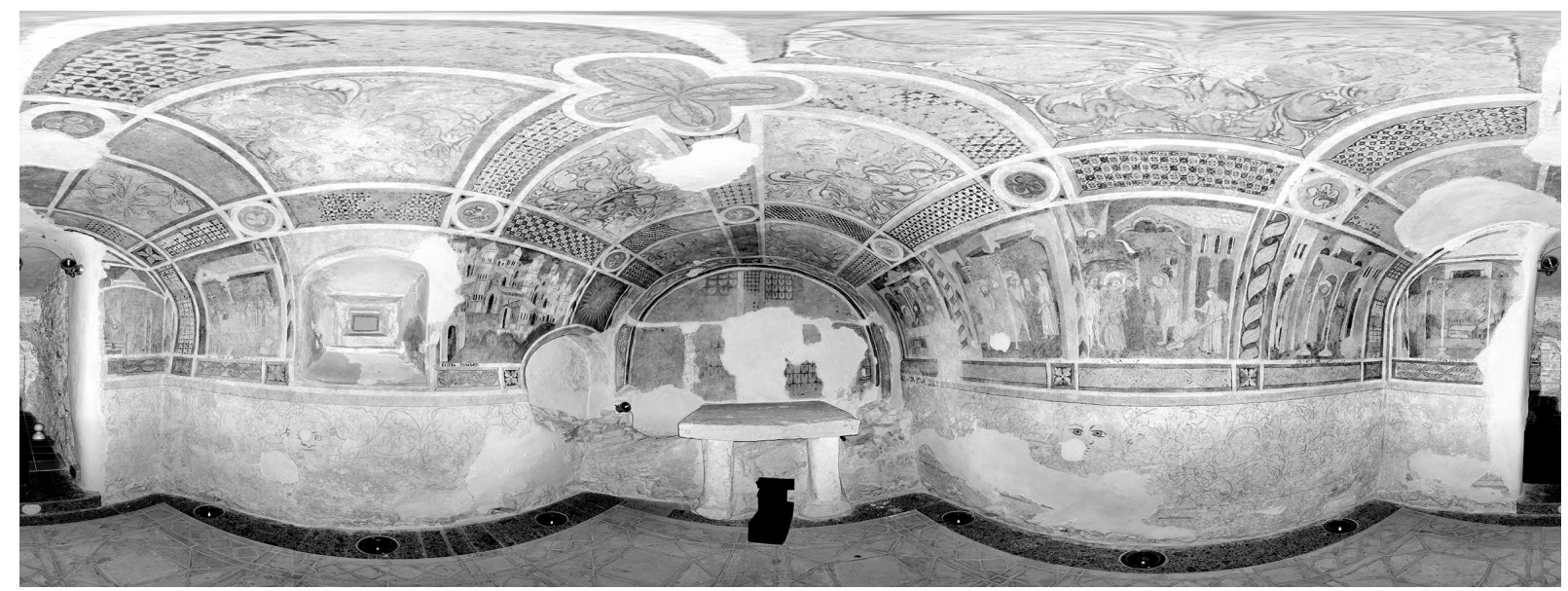

Figure 1. The equirectangular projection of the small chapel performed with a phase-based laser scanner. 


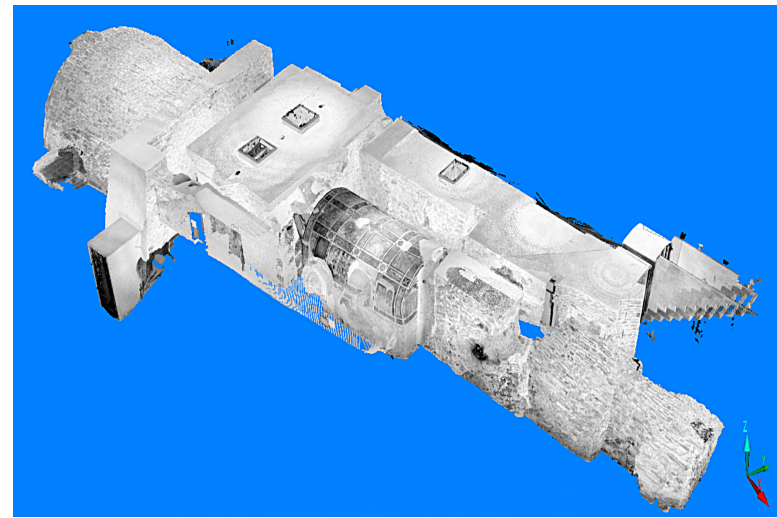

Figure 2. The hypogea system under the church. The scans were registered together for a complete view of this particular spatial distribution.

information about the history of the archaeological complex through innovative point of views.

\subsection{Archaeological hermeneutics}

The chapel of the works of mercy is located in the village of Sant'Angelo in Grotte (Italy), in the hypogeum of the parish church of S. Pietro in Vincoli.

The façade of the church is characterized by an inscription that remembers its construction, made in 1883 on the ruins of the previous church [TEMPLUM HOC / PENITUS COLLAPSUM / MUNICIPII SUMPTIBUS / ARCHIPRESBJTER / FEDERICUS TADDEI / AB IMO / ERIGENDUM CURAVIT / MDCCCLXXXIII / Nazarius Frantiello fecit]. This represented only the last reconstruction of the church that in 1456 and in 1805 suffered two devastating earthquakes.

For the first time in 1954, during pavement removal works, hidden and forgotten cavities were discovered again (Valente, 2003). A small chapel with a rectangular plan covered by a barrel vault was found. The surfaces of the chapel were completely painted with representation of the spiritual works of mercy. The pictorial cycle is characterized by a series of frames that host different scenes on the same theme, in a clockwise direction, starting from the right of the small altar.

The dating of the pictorial cycle can be positioned between the end of the XIV ${ }^{\text {th }}$ century and the beginning of the $\mathrm{XV}^{\text {th }}$ century (Marino, 2013; Marino, 2013a). In that period the presence of two feudal lords, Filippo and Angelo (of Santangelo) related to the ruling family of the d'Angiò, is testified.

In another room, near the chapel, further pictorial traces were unveiled. They represented a pictorial cycle completely lost, probably due to the earthquakes that tragically marked the life of the monument.

The chapels are part of a series of hypogean systems that the last excavation and restoration works have re-arranged, losing every possible reconstruction of the original mutual relationship with the upper church (Fig. 2). The result is an artificial structure that allows to visit different spaces without functional relations.

The stylistic characteristics of S. Pietro in Vincoli confirm that the current church appears a recovery of a structure of the previous century (Fig. 3). After the first earthquake the church was built again and probably, in the Baroque period, the church was renovated due to the damages of time.

These hypotheses should be verified and commented through historical and archaeological investigations.

\section{THE SURVEY OF THE HYPOGEA SYSTEM}

\subsection{The acquisition and processing phases}

A phase-based laser scanner was used for surveying the entire church and hypogea systems. The scans were performed completely in the dark for registering the morphological data and favouring an homogeneous acquisition of the painted surfaces with reflectance information (Vosselman, Maas, 2010; Remondino, Campana, 2014).

The reflectance value represents the highest resolution of the clouds set up from the user during data acquisition even if it is not an absolute value (Docci, Maestri, 2012). However the reflectance aids the readability of a monument, its details such as important paintings. Considering the literature available, no test on laser scanner accuracy were carried out (Boehler et al., 2003). For the entire project a total of 25 scans were performed with an indoor resolution. High resolution was set up only for the two chapel with pictorial information.

With an high definition full-frame camera (Canon Eos 5D RS), a fixed optic lens $(28 \mathrm{~mm})$ and a colour checker, several images of the main chapel were taken in order to control the chromatic appearance of the paintings and the homogeneity of the lighting sources (Devebec, Malik, 1997; Cattaneo et al., 2014). For detailed analysis and for documenting their current condition the frescoes and the paintings need to be represented in high resolution (the resolution of each image was $50 \mathrm{MP}$ ).

The scans were merged using Cloud to Cloud registration algorithms (C2C). Such algorithms are known as Iterative Closest Points (ICPs; Chen, Medioni, 1991). Despite they have been already developed in the 90 's, different implementations have made them common for the software of 3D point clouds managements (Besl, McKay, 1992; Rusinkiewicz, Levoy, 2001) After a pre-registration step, performed manually, ICPs are able to move a point cloud over another point cloud (the reference one) on the basis of thousands of points (statistical method), thus reducing the final overlapping error. The ICP algorithm works with structured data, and where present, the GUI (Graphic User Interface) is composed by different values that can be changed by the user. In order to satisfy the algorithm two structured scans have to be pre-registered manually on the basis of 3 or more points. The mutual starting distance between the

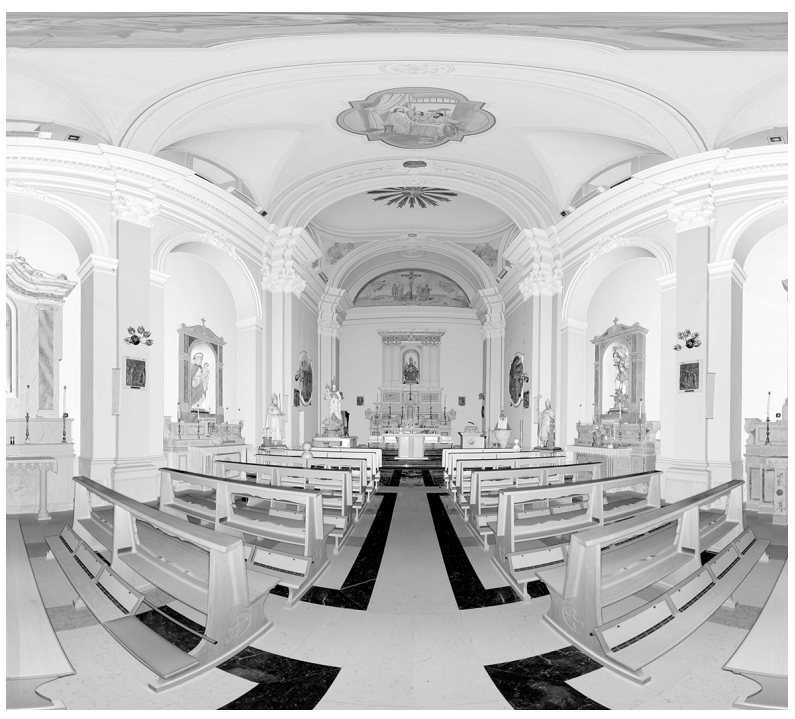

Figure 3. The late church of S. Pietro in Vincoli. 
scans can influence the quality of alignment and the number of iterations.

This approach allowed to change completely the procedure during the acquisition step. At present, it is more important to have a good overlap (60\%) among the subsequent point clouds in order to satisfy the requirements of the ICP algorithms. The ICP registration allows to reduce the spread error up to a few millimetres, effectively excluding a topographical approach. The use of topography depends also on the case study, considering the extension and the complexity of an architecture. The risk is that the acquisition of the GCPs with a total station would increase the registration error among the scans. Eventually the topographical approach could be used only for georeferencing different scan projects in the same reference system. The last step consisted in the bundle adjustment, a further processing that redistributes the remaining errors among the entire scan project.

\subsection{The surface reconstruction}

The surface reconstruction was performed for reducing the number of points, maintaining however a good quality of the morphology (Fig. 4; JRC Reconstructor 3, Development Team 2018; Canciani et al. 2013). In particular, the surface model of the chapel was generated with a greater number of triangles for a better definition of the decorations using the multi-resolution grid algorithm (Sgrenzaroli, Vassena, 2007). This algorithm is able to reconstruct surfaces exploiting the information generated in the pre-processing step. In particular surface orientation and depth discontinuities are used to calculate the size of the triangles, distinguishing flat areas from complex areas. For the edges the reconstruction method increases the number of the triangles and reduces their dimension. Further values can be modified for defining the ratio of the triangles and their accuracy related to the cloud.

The algorithm is reliable above all for large-scale subjects like in the architectural discipline. No refinement or optimization methods were applied to the surface model, considering the simple shape of the barrel vault and the small size of the chapel. No other reconstruction algorithms were tested to improve the shape and simplify the model.

The "multi-resolution" method was applied for the entire

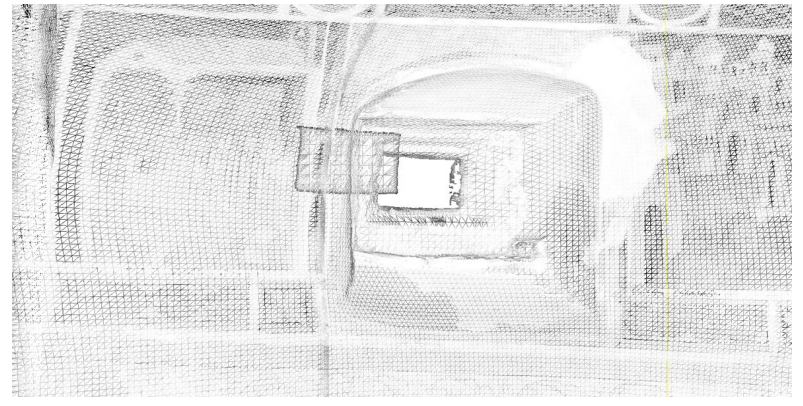

Figure 4. Multi-resolution grid algorithm allowed to reconstruct the entire numerical model according to different resolution.

numerical model in order to reconstruct differently the geometry of the rupestrian architecture, evidencing the details but maintaining a manageable model.

\section{THE REPRESENTATION OF THE HYPOGEA SYSTEM}

\subsection{The representation of the rupestrian architecture}

In architecture it is often necessary to represent different levels in order to evidence the vertical relationship of a structure, both in relation to the connecting elements, and to understand the mutual morphological and static relationships

Furthermore, the preponderant sculptural nature of the rupestrian architecture does not allow a traditional representation of sections and projections of edges and outlines. Experimented in different projects in Italy and Turkey, the Equidistant Multiple Sections (EMS) allow to exploit the representation methods for the shape analysis of the rupestrian architecture. The technique is inspired by cartography, in which the territory is represented by means of "contour lines" (isohypses) with constant difference in level (equidistance). In addition to the planar distribution, the EMS system is able to evidence the altimetry of a subject, thus showing also the third dimension (Fig. 5).

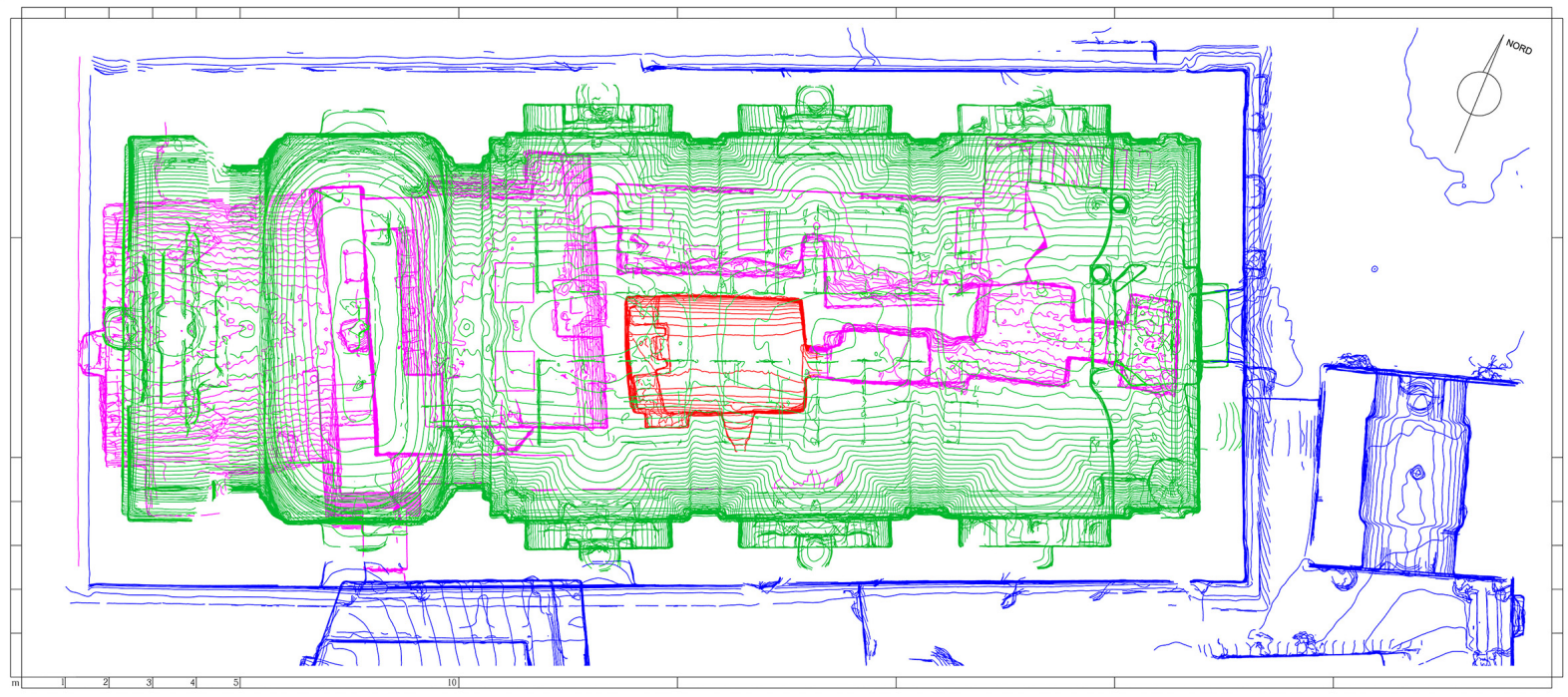

Figure 5. The application of the EMS system for the entire church and for the hypogea system. 


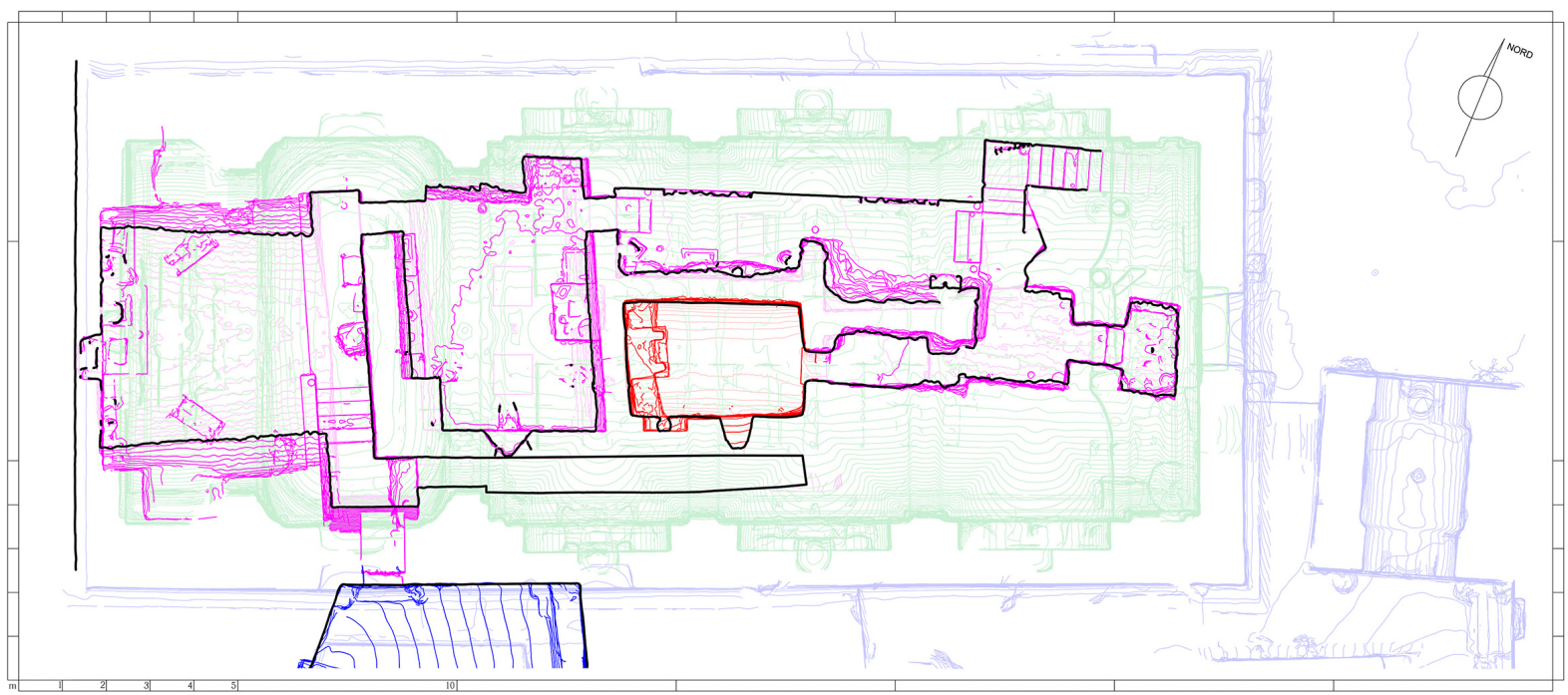

Figure 6. Each level can be represented according to a specific depth, evidencing the objective characteristics of the architecture.

In cartography equidistance is equal to $1 / 1000$ of the denominator of the representation scale in meters. An equidistance of $5 \mathrm{~cm}$ can therefore be set for a canonical architectural representation of 1:50, although a double distance $(10 \mathrm{~cm})$ allows the isohipses to describe the architectural forms without generating crowding lines.

The EMS system can also be applied for vertical representations, setting the appropriate positions of the main plane and in consideration of the prevailing geometries.

The contour lines system was used for the first time in 1960s for the representation of the Abu Simbel sculptural subjects (Carbonnell, 1972; Fondelli, 1992). Thanks to the stereoscopic photogrammetry it was possible to generate accurate representations of the large statues for the subsequent cutting project.

Even if the method has remained the same, the current IT tools have allowed to increase the possibilities of study and analysis. For instance each level of the representation can be highlighted with different colours (Fig.6). This allows to have, in a single drawing, the distribution of several levels, thus preserving both the possibility of reading the relationships of the plane and the vertical relationships.

\subsection{A different approach for the texture mapping process of the chapel}

One of the aim of the paper is to experiment different solutions in the texture mapping process for unstructured surface models (Cipriani, Fantini, 2015). Texture mapping process is used to relate the structure of a $3 \mathrm{D}$ numerical model with the pixel of a bitmap image through a biunique correspondence, using UV maps (Remondino, El-Hakim, 2006). In order to accomplish the process it is important to establish the correspondences, identifying a sufficient number of homologous points between the image and the point cloud. The complexity of the shapes of an architecture can influence the choice of the points and their number. The points should be identified in representative elements of the architecture for avoiding geometric scene distortions. Even if the chapel was represented by a rectangular plan and a barrel vault, the main problem consisted in the image projection, considering the reduced size of the chapel that measures only $3.70 \mathrm{~m}$ in length, $2.5 \mathrm{~m}$ in width and $2.5 \mathrm{~m}$ in height.
The surface model was mapped with high resolution images through a different approach. Usually the image projection is performed directly on the point cloud in the 3D model space or visualizing the ecquirectangular projection of the scan with the reflectance information associated (planar representation at very high resolution; Carpiceci et al., 2018).

In the model space the recognition of the points is very difficult to select, considering the all-round view of the point clouds and the impossibility to zoom the model for a detailed view, conditioned from the resolution and the distance between the points.

The limit of the equirectangular projection is the difficulty of editing the image that is subjected to deformation, above all at the poles, so that most of the points are recognized in the central part of the image (equatorial; Fig. 7). In the chapel (in general in closed spaces) many problems occurred for the correct identification of points, above all for the barrel vault and the

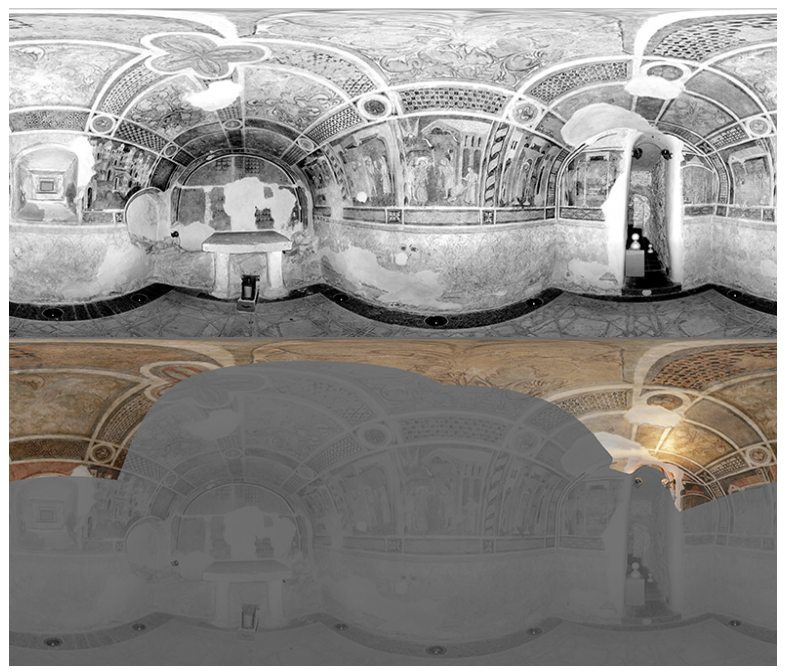

Figure 7. The image show deformations that occur in the planar representation of the cloud. The presented system allows to maps correctly images of the barrel vaults. 
side walls very close to the laser. To avoid deformations usually ecquirectangular images are transformed in cubic projections and processed.

An interesting experimentation was tested for analyzing from a different point of view the problem that occurs in the deformation of the vaults, exploiting a tool developed by Gexcel and named "virtual scan" (Sgrenzaroli, Vassena, 2007).

The tool allows to make a virtual scan of a subject in the model space by using different projection systems such as orthographic, cylindrical, spherical and perspective cameras in any virtual position established from the user. Once a camera that includes the model is established (independently from the structure), the whole point cloud can be virtually acquired at a desired resolution, simulating the same acquisition method of a laser scanner. Although the resolution of the result depends also on the graphic card, it is possible to create a new structured 3D numerical model of the subject with similar characteristics of the source point cloud really surveyed (Angelini, Portarena, 2017).

Virtual Scan tool is normally used for generating orthophoto of the model and for integrating shadow areas in the surface model, re-sampling the clouds. A specific applications was experimented for generating metric photos of an architectural subject (Dequal, 2003). For the paper the experimentation was tested for a different approach in the image projection process, in an unconventional way.

A perspective camera was created with similar FOV $\left(80^{\circ}\right)$ and position of the reflex used for acquiring images (Fig. 8). This expedient was used for facilitating the identification of the points, avoiding different orientation between the image and the point cloud in the software graphic interface.

A virtual scan was performed for generating a new structured cloud with the same orientation, similar resolution (4 million of point) and without any deformation in the 2D structured image (planar representation). The process emulates a photographic acquisition of the cloud using the properties of a laser scanner.

The new grid model was used to perform the calibration step and the subsequent projection. The calibration phase was repeated for each image in order to solve the orientations (interior and exterior).

The re-projection error influences the general quality of the result, most evident in the overlapping areas. High projection errors generate blurry areas. The following results emerged from the comparison with the "traditional" system:

- the new approach favoured the recognition of the homologous points necessary for the full calibration (OpenCV model), thanks to the same orientation and area between the image and the new point cloud;

- the most recognizable points and their geometrical disposition reduced the projection error of the entire process and improved the position of the projector. The latter is represented from the coordinate of virtual projection centre $\left(\mathrm{X}_{0}, \mathrm{Y}_{0}, \mathrm{Z}_{0}\right)$. From the figure it is possible to notice the old and the new position of the projector before and after the new approach (Fig. 9);

- the new grid model allow to exploit all the area of each image optimizing the geometric disposition of the points that can be correctly managed;

- the use of the tool allows to map adequately the ground and the vaults that are subject to deformation, maintaining the same accuracy adopted for the side wall.

The barrel vault of the chapel was completely mapped with this method. Further experimentations were performed for complex
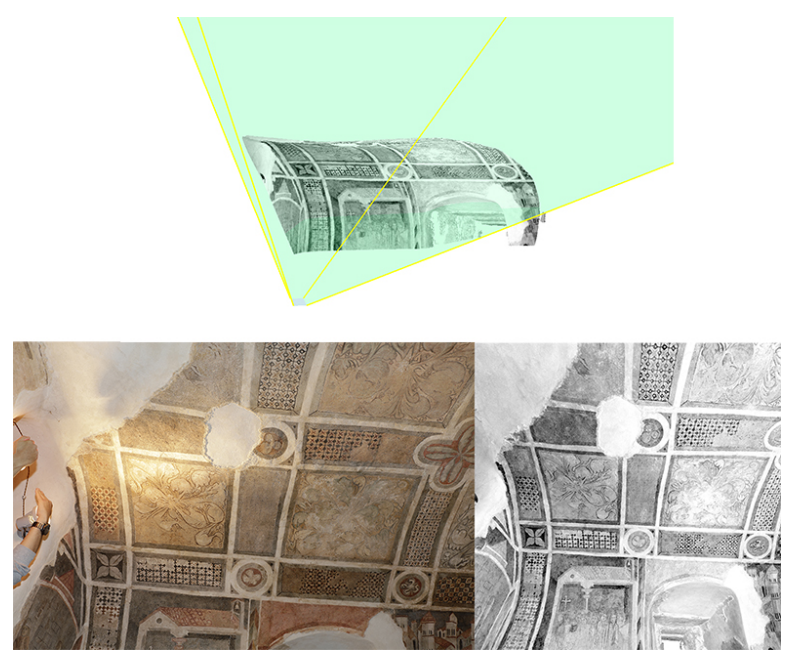

Figure 8. On the left the image from the camera, on the right the cloud from virtual perspective camera. The same orientation and area favoured the points recognition.

shapes, with the support of the photomodeling and the creation of a virtual orthographic camera.

Some considerations were evidenced about the projection errors between an orthopohto (photomodeling) and multiple images. From a scaled point cloud an high resolution orthophoto was generated, for mapping wider surface (with a length of $10 \mathrm{~m}$ ). The idea was to use this new approach for surfaces poor of recognizable points due to their colour homogeneity. Apparently the system could be used in reliable way for mapping the surfaces but some errors in the orthophoto projection do not allow an effective use of the method:

- the orthographic projection is oriented towards the infinite. After the calibration step this characteristic generates the projector (projection centre) out of the numerical model. In this way the final image is mapped on the wrong side (in the specific case on the floor and not on the vault). To avoid this problem it is necessary to separate the cloud into two distinct models, one

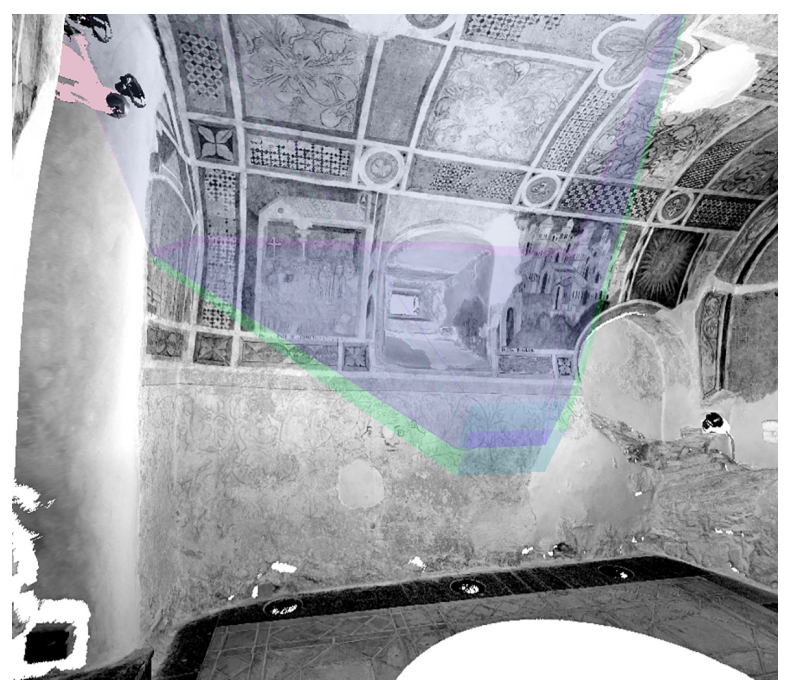

Figure 9. In the image it is possible to view the different position of the projector before (green) and after (blue) the virtual scan processing. 


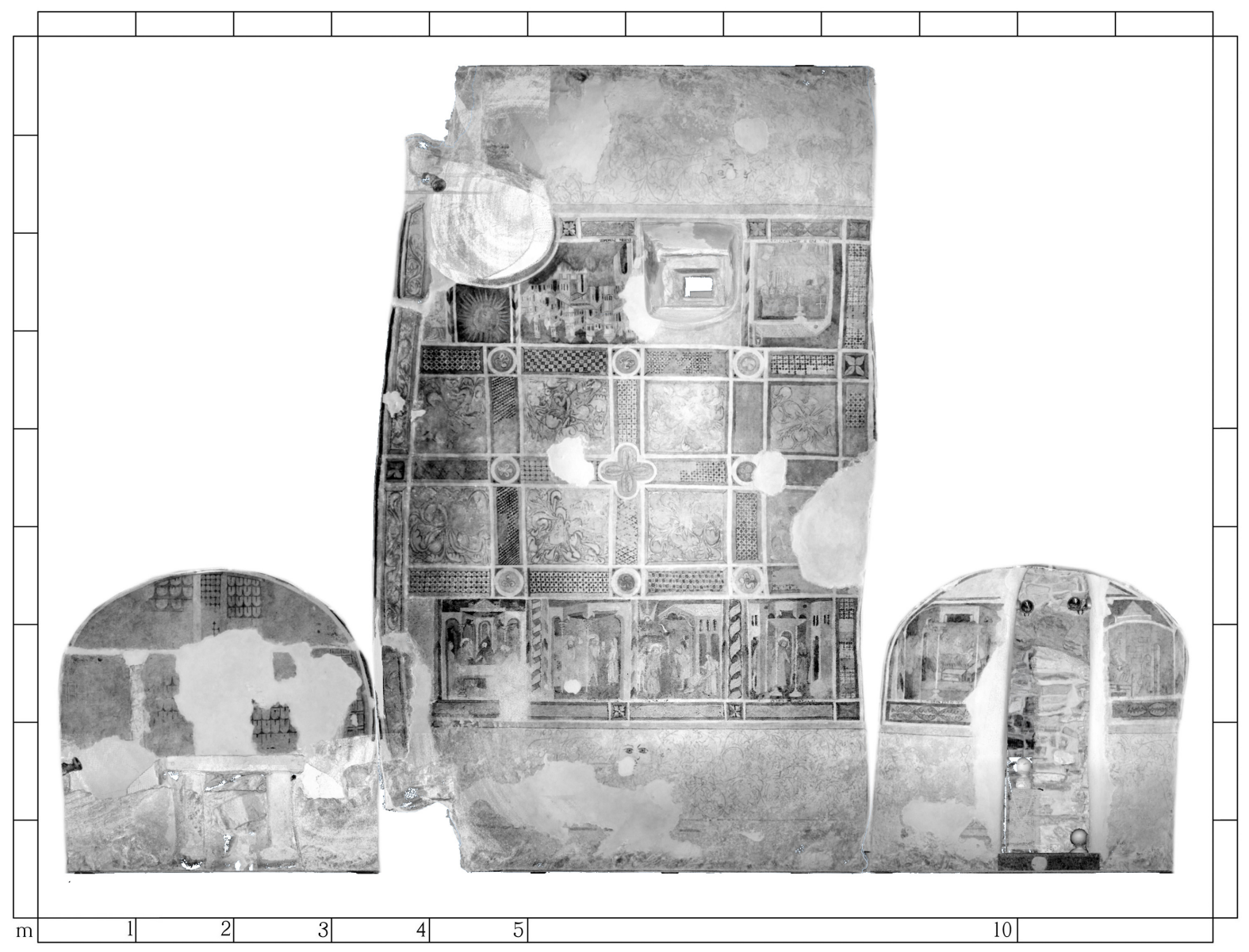

Figure 10. The barrel vault of the chapel was completely unfolded for observing the real shapes of the pictorial decorations.

for the floor and one for the vault, increasing processing times;

- the second problem consisted in the final 3D representation. The area included between the spring and the haunch of a barrel vault is flattened in the orthophoto so that during the image projection many parts are stretched and difficult to manage;

- on flat area such a wall the results are good and fast, but in surfaces with a lot of discontinuities the results are very difficult to manage for the intrinsic characteristics of the orthographic representation.

\subsection{The unfolding surfaces}

Decorated surfaces often need to be represented for preserving their apparent appearance compared to the original. For the Cultural Heritage the point clouds of a laser scanner are not comparable to precise and simple geometries. Often it is necessary to re-organize the structure of the surfaces in order to make the representation simpler.

In general surfaces can be distinguished in two large families: straight lines surfaces and spheroidal surfaces. For the spheroidal the stereographic projections derived from cartography are used besides other form of projection studied in the past and recently updated (Marks, Fuller, 1960;Van Wijk, 2008). A detailed study of the problem for Cultural Heritage applications has not been undertaken.
For the straight lines surfaces, cylindrical and conical, the unfolding is mathematically possible. This is the case of the barrel vault of the works of mercy chapel (Fig. 10). The adopted procedure for unfolding the vault is not mathematical but projective, and is however able to maintain the accuracy and above all the achievement of a representation that corresponds to the original.

In this way an original vision has been obtained, which possesses all the metrical data and preserves all its "formal" relations.

\section{ACKNOWLEDGEMENTS}

The paper is the result of the collaboration between the authors. In particular Laura Carnevali developed the paragraphs $\mathbf{1 . 2}$ and 2.1, Marco Carpiceci the paragraphs 1.1, 2.1, 3.1, and 3.3, Andrea Angelini the paragraphs 2.1, 2.2 and 3.2. All the authors have contributed equally to the survey campaign.

\section{REFERENCES}

Angelini, A., and Portarena, D., 2017. A procedure for point clouds matching from range-data and image-based systems. The e-Journal of the International Measurement Confederation, Acta IMEKO, 6(3), pp. 57-66. 
Besl, P.J., and McKay, N.D. 1992. A Method for Registration of 3-D Shapes. IEEE Transaction on Pattern Analysis and Machine Intelligence, 14(2), pp. 239-256.

Boehler, W., Bordas, M.V., and Marbs, A. 2003. Investigating laser scanner accuracy. In: CIPA 2003 XIX ${ }^{\text {th }}$ International Symposium: new perspectives to save cultural heritage, Antalya, Turkey, pp. 696-701.

Canciani, M., Falcolini, C., Saccone, M., and Spadafora, G., 2013. From point clouds to architectural models: algorithms for shape reconstruction. The International Archives of the Photogrammetry, Remote Sensing and Spatial Information Sciences, Trento, Italy, Volume XL-5/W1, pp. 27-34.

Carbonnell, M., 1972. Levés architecturaux et archéologiques. In: Photogrammtrétrie générale, Éditions Eyrolles, Paris, Tomo 4, pp. 286-312.

Carpiceci, M., and Inglese, C., 2015. Laser Scanning and Automated Photogrammetry for the knowledge and the representation of the architecture cave in Cappadocia: Sahinefendi and the Open Air Museum in Goreme. In: CAA 2014: $21^{\text {st }}$ Century Archaeology Concepts, methods and tool. Proceedings of the $42^{\text {nd }}$ annual conference on Computer Applications and quantitative methods in Archaeology, Paris, France, pp. 87-94.

Carpiceci, M., Russo, M., and Angelini, A., 2018. The digital model of the S. Zenone chapel inside Santa Prassede in Rome. A case study for the morphological analysis. In: VSMM2017, $23^{\text {rd }}$ International Conference on Virtual Systems and Multimedia : Through the Looking Glass - Back to the Future of Virtual Reality, Dublin, Ireland, in press.

Cattaneo, A., Curuni, S.A., and Santopuoli, N., 2014. L'utilità della fotografia per la comprensione dell'organismo architettonico. Felici Editore, Roma.

Chen, Y., and Medioni, G., 1991. Object Modeling by Registration of Multiple Range Images. In: Proceedings of International Conference on Robotics and Automation, Sacramento, California, vol. 3, pp. 2724-2729.

Cipriani, L., and Fantini, F., 2015. Structure from Motion digital models to develop a cognitive system of the porticoes in Bologna. Drawing. Ideas. Images, 50, pp. 70-81.

Dequal, S., 2003. Struttura dell'immagine solida. Bollettino SIFET, 1/2003, pp. 67-76.

Devebec, P.E., and Malik, J., 1997. Recovering high dynamic range radiance maps from photographs. In SIGGRAPH ' 97 The $24^{\text {th }}$ International Conference on Computer Graphics and Interactive Techniques, ACM, NewYork, pp. 369-378.

Docci, M., and Maestri, D., 2012. Manuale di rilevamento architettonico e urbano. Laterza, Bari, pp. 225-226.

Fondelli, M., 1992. Trattato di fotogrammetria urbana $e$ architettonica. Laterza, Roma-Bari.

Marks, R., Fuller, R.B, 1960. The Dymaxion World of Buckminster Fuller. Reinhold Publishing, New York.

Marino, V., 2013. Sant'Angelo in Grotte e la Carità cristiana: gli affreschi della chiesa di San Pietro in Vincoli. Altri Itinerari, 10(23), pp.50-63.

Marino, V., 2013a. Gli affreschi delle opere di Misericordia corporali e del Cristo Pantocratore a Sant'Angelo in Grotte e rapporti con Roccaravindola e Pizzone. Studi Medievali e Moderni, 17(1), pp. 269-297.

JRC Reconstructor 3 Development Team, 2018. Gexcel, Joint Research Centre, Version 3.2.0.552.

https://www.gexcel.it/en/software/jrc-3d-reconstructor/full-fulleducational

Remondino, F., and El-Hakim, S.F., 2006. Image Based 3D Modelling: a review. The Photogrammetric Record, 21(115), pp. 269- 291.

Remondino, F., and Campana, S., 2014. 3D Recording and Modelling in Archaeology and Cultural Heritage - Theory and best practices. BAR International Series 2598, Oxford, pp. 2764.

Rusinkiewicz, S., and Levoy, M., 2001. Efficient variants of the ICP algorithm. In: Proceedings of Third International Conference on 3-D Digital Imaging and Modeling, Quebec City, Canada, pp. 145-152.

Sgrenzaroli, M., and Vassena, G.P.M., 2007. Tecniche di rilevamento tridimensionale tramite laser scanner, Volume 1 Introduzione generale. Starrylink Editrice, Brescia.

Van Wijk, J.J., 2008. Unfolding the Earth: Myriahedral Projections. The Cartographic Journal, 45(1), pp. 32-42.

Valente, F., 2003. Luoghi antichi della provincia di Isernia. Edizioni Enne, Bari.

Vosselman, G., and Maas, H.G., 2010. Airborne and Terrestrial Laser Scanning. Whittles, Caithness. 